\title{
Experimental Study of Upstream Fan Broadband Noise Radiated by a Turbofan Model
}

\author{
Serge Lewy \\ Office National d'Etudes et de Recherches Aerospatiales (ONERA), MB 72, 92322 Chatillon, France
}

(Received 25 September 2000; accepted 11 February 2001)

\begin{abstract}
Broadband fan noise has become the major component of the sound radiated by high bypass ratio turbofans because of the past progress in the reduction of the tones. New analysis is presented of the tests performed in the framework of the European project FANPAC to obtain more information on the generation and radiation of broadband noise. It is explained first how to isolate this component from the tones in the far-field acoustic spectra measured upstream of the fan. Next, the overall sound pressure directivities and sound power levels are reduced for the basic configuration. The sound power increases as the blade tip velocity to the fifth power, and by $1.6 \mathrm{~dB}$ per degree increase in blade angle of attack. Other configurations are then considered. It is shown that flow distortions, either due to the removal of the turbulence control screen or to a droop inlet, only have a minor effect on broadband noise, increasing its level by about $1 \mathrm{~dB}$. Finally, an acoustical lining on the duct wall is used to effectively absorb the multiple pure tones at supersonic tip speeds. It can be inferred that the mechanisms of broadband noise generation are similar at both subsonic and supersonic flows.
\end{abstract}

\section{NOMENCLATURE}

a $\quad$ - speed of sound

$B \quad$ - number of rotor blades

C - constant for adjusting the centre frequency of the semi-empirical broadband spectrum

$D \quad$ - fan diameter

$f \quad$ - frequency

$g, \varphi \quad$ - amplitude and phase of the reflection coefficient on the inlet flare

$L \quad$ - duct length

$M_{a x} \quad$ - axial Mach number near the blade tip

$M_{\text {hel }}=\sqrt{M_{\text {tip }}^{2}+M_{a x}^{2}}$. Helical tip Mach number

$M_{\text {tip }}=\pi D N / a$. Rotational tip Mach number

$N \quad$ - fan rotation speed (either in $\mathrm{rpm}$ or in $\mathrm{Hz}$ )

$n \quad$ - order of the harmonic of the blade passing frequency

$r \quad$ - distance of far field microphones to the fan intake centre

$W \quad$ - sound power

$\Delta f \quad$ - spectral bandwidth

$a \quad=\Delta f / f$. Relative bandwidth

$\theta \quad$ - angle of far field microphones $(0 \mathrm{deg}$ on the fan inlet centreline)

$\rho_{0} \quad$ - density of air

$\sigma \quad$ - standard deviation of the semi-empirical broadband spectrum

$\psi \quad$ - angle of incidence of flow onto the blades

d - design conditions

rms - root mean square value

$\mathrm{BPF}$ - blade passing frequency $\left(f_{1}=B N\right)$

HWL - high working line

LWL - low working line

MPT - multiple pure tones (harmonics of the shaft rotation frequency, $N$ )

OASPL - overall sound pressure level (frequency integrated SPL)
OAPWL - overall sound power level (spatially integrated OASPL)

SPL - sound pressure level

PWL - sound power level (spatially integrated SPL)

TCS - turbulence control screen

\section{INTRODUCTION}

The fan is the main source of noise in high bypass ratio turbofans. A great deal of effort has been devoted during the past decades to reduce the tones, by decreasing the rotorstator interactions and improving the sound absorbing efficiency of the acoustical linings on the walls of the nacelle. Progress has been such that sound levels due to tones have become lower than that of the broadband component in modern engines. ${ }^{1,2}$ Gliebe has written: "Some preliminary calculations indicate that, for a typical modern turbofan, if one could completely eliminate all fan tones, total system noise would only be reduced by 0.5 to $1.5 \mathrm{EPNdB}$, depending on the operating condition". ${ }^{2}$ Prediction and control of turbomachinery fan broadband noise is now the main challenge in the design of quieter fans. There are few theoretical and experimental studies that can be applied directly to turbofans. Less than one page is devoted to this issue in an outstanding review on turbomachinery noise. ${ }^{3}$ This situation was confirmed recently in a paper written by a scientist at the NASA Glenn Research Center. ${ }^{4}$ Some extensive tests on a model scale fan were carried out only recently by Boeing to investigate the various sources of broadband noise. ${ }^{5-8}$

The present study has been made in the framework of the European project RESOUND (Reduction of Engine Source Noise through Understanding and Novel Design). It is based on tests conducted in the framework of the preceding European project named FANPAC (Aeroacoustics Methods for Fan-Noise Prediction and Control). Tests were made by Rolls-Royce in the Ansty Noise Compressor Test Facility (ANCTF), and the experimental set-up has been fully described in previous papers (see Fig. 1). ${ }^{9,10}$ Tests were per-

International Journal of Acoustics and Vibration, Vol. 6, No. 2, 2001

(pp 65-75) 